\title{
A Novel Simulation And Test Program For Secondary System In Intelligent Substation
}

\author{
Tangzhijun $^{1}$, Zhaibolong $^{1}$, Linguodong $^{1}$, Chaowujie $^{1}$ \\ 1. State Grid Fujian Electric Power Research Institute, Province Fujian, China \\ 13705004007@139.com,zhaibolong@163.com,chaowujie1013@163.com
}

Keywords: intelligent substation; secondary system; simulation test

\begin{abstract}
With the rapid development of Chinese electric power technology (or in China), intelligent substation has become the trend of development. But the long test cycle of existing system in intelligent substation, many debugging equipment and involving links and complex work, has a great impact on the construction project of efficiency intelligent substation. According to this case, this paper proposes a new intelligent substation equipment simulation test program, firstly analysis the overall system architecture, and next, the techniques of equivalent simulation and simulation test being used in intelligent substation secondary equipment. Furthermore, the key technologies of intelligent substation secondary system simulation test program are also discussed. And the test results show that: the intelligent substation secondary system simulation test program is fully capable to achieve the requirements of protective device and expected test, greatly improving the test efficiency.
\end{abstract}

\section{Introduction}

With the rapid development of electric power technology in China, intelligent substation has become the development trend of the substation. The intelligent substation not only can monitor the operation of traditional power network, but also has the advanced application, such as data identification, intelligent alarm, integrated five control, reactive power optimization control, sequence control, greatly improving the efficiency of the production and operation of the substation, reducing operation and maintenance workload of operators, and ensuring the reliable, stable and safe operation of power grid [1].

The key design of the secondary subsystems of the intelligent substation is based on the IEC61850 standard of the digital modeling and network communication, the intelligent substation's the secondary system structure, secondary system debugging, process of system construction, secondary system modeling has taken great changes compared with the traditional substation, and the main difference lies in the transmission of information, network and digital information exchange [2].The key of the secondary system interoperability in the intelligent substation has become the communication between the Optical Ethernet and the switches. However, the existing intelligent substation secondary system test mode is: firstly, prepare all secondary equipment of process, spacer layer, station control layer, and complete the monomer debug and configuration of these equipment; secondary, link the digital network and virtual terminal configuration of the secondary system of the intelligent substation; thirdly, complete the signal transmission and the point test of secondary subsystems of the intelligent substation, and complete the configuration of the application of the monitoring system; fourth, start the test of secondary system of intelligent substation. As a result, the debugging and test cycle of the secondary subsystems of existing intelligent substation is long, and it will need many debugging equipment and the complex work, which have a serious impact on the construction efficiency of the intelligent substation project [35]. This paper presents a new simulation and test scheme of secondary system of intelligent substation, which provides a new idea of practicability, universality and standardization to achieve secondary system debugging of intelligent substation, and improves the efficiency of intelligent substation construction.

\section{The whole structure of the simulation and test scheme for the secondary equipment of Intelligent Substation}

The simulation and test scheme for the secondary equipment of intelligent substation consists of integrated substation automation system, time synchronization system, engineering simulation test system, process simulation subsystem, interlayer simulation subsystem etc.

(1)Time synchronization system use GPS or Beidou manner, supporting B code, PPS second pulse and IEEE 1588 time synchronization protocol, and can also be flexibly configured. (2)The engineering experiment simulation and test system, which is located in the station control layer, including the station control layer simulation and test subsystem, is the key system of the platform. This system realizes the intelligent analysis of SCD files in Substation, the graphical display, the status display and the configuration query of the secondary equipment, editor of primary equipment wiring diagram in substation; realizes the SCD configuration file version management, SCD file standardization inspection; the construction and management of intelligent expert test bank in intelligent substation, implementation of monomer test of 
substation secondary equipment, the testing of relay protection, control, measurement, the whole system etc.

(3)Interlayer simulation testing subsystem contains protective simulation module, measurement and control simulation module, metering simulation module and the interlayer test module, to realize the simulation of protection system, measurement system and control and measurement system, and the equipment testing and system debugging testing of protection, control, measurement system.

(4)The simulation and testing subsystem of process layers includes the merging unit simulation module, intelligent terminal simulation module and process layer test module, it mainly realizes the simulation of merging unit, intelligent terminal equipment, it support the construction of many network mode of SV, GOOSE in process layers, such as the direct mining point-to-point, packet network, and the monomer test the merging unit, intelligent terminal spacer, it can also complete the testing of protection, control and measuring systems.

\section{A novel testing technology in the Intelligent Substation Secondary System}

To solve the existing problems of Intelligent Substation Secondary System, this paper puts forward a point of equivalent simulation test. Logically, the intelligent substation secondary system test is divided into three parts, "Application functions of the input and output", "Application functions under test", "Equivalent Execution and Equivalent Collection", breaking the previous ideas integrated debugging testing. The logical structure of Intelligent Substation Secondary System equivalent simulation test was shown in Fig. 1.

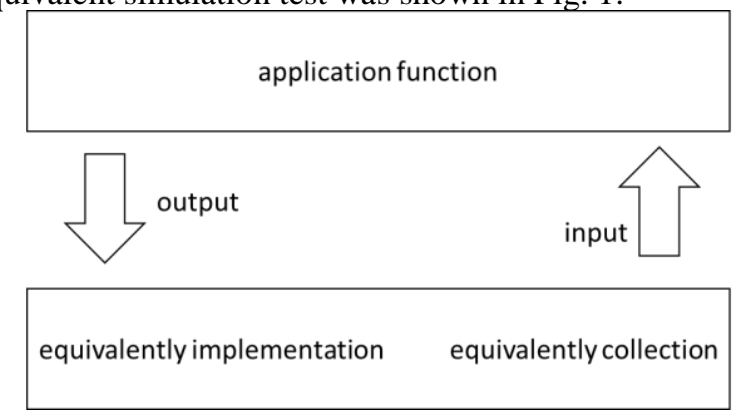

Fig. 1 The logical structure of Intelligent Substation Secondary System equivalent simulation test.

Based on the idea of equivalent simulation test, Intelligent Substation Secondary System takes "Integrated debugging and application functional testing" as center to analysis, redividing the function integration tests of intelligent substation secondary system, and abstracting equivalent simulation test system of the secondary equipment object [6]. The upper application integration of advanced debugging and testing can be supported by the control objects and acquisition objects of intelligent substation secondary equipment; and then, the control commands and data acquisition of Intelligent substation secondary equipment data object can support the pre-communication test of lower secondary equipment.
The secondary system supporting the input and output portions of the function under test can be completely equivalent replaced based on equivalent simulation technology, intelligent substation secondary system can be separated effectively and integrated debugging and it can also complete full simulation test. The simulation integration testing of the Application function of various parts in the intelligent substation secondary system can be achieved by equivalent simulation system instead of the real device's support. It is noteworthy that, if the supports for upper and next of equivalent simulation tests system of secondary equipment agree well with each other, then the entire system integration testing can be completed. As a result, this new mode of intelligent substation secondary equipment simulation test program can greatly improve the efficiency, shorten the debug test cycle effectively, and further promote the application and promotion of advanced features of intelligent substation. [7]

The same way can also be used into the test of bay layer in the secondary equipment, the output and input of the measured bay layer will be replaced by the secondary simulation system, furthermore, the mixture of actual integrated debugging physical device and secondary simulation system can be realized. The full simulation test between the bay layer devices can be achieved ensuring that the actual physical device is consistent with the input and output of the secondary simulation system, as shown in Fig. 2.

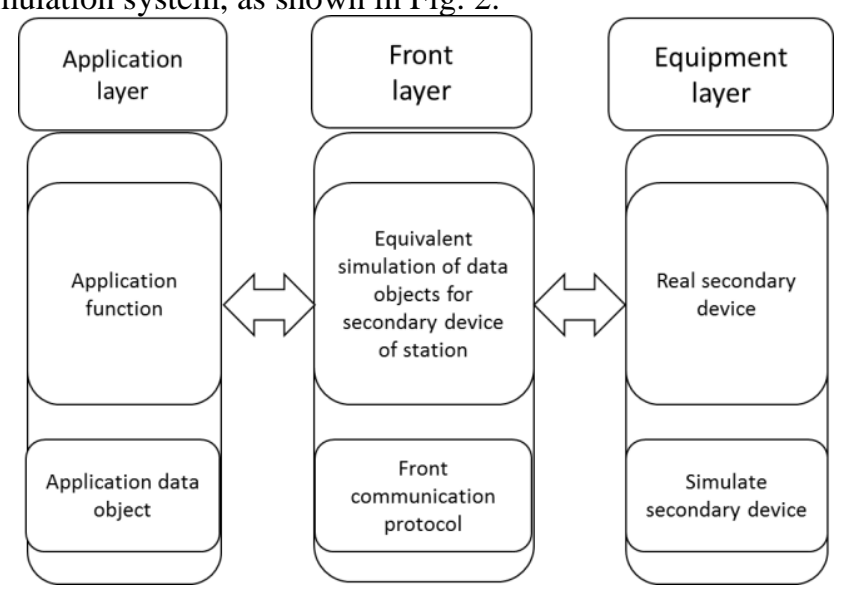

Fig. 2 Equivalent Simulation Test of Intelligent Substation Secondary System

\section{The Key Technology of Intelligent Substation Secondary System Simulation Test}

\subsection{General simulation technology of secondary equipment based on common platform}

Bay layer secondary equipment simulation system can be used to simulate various types of monitoring and control and protection devices by general simulation technology of secondary equipment. Based on the common operating system and hardware platform, the common multi-device simulation can be supported by the secondary device simulation system , using multi-IP technology, shared memory technology and 
multi-thread technology. And the protection logic, software attributes and hardware configuration of each type secondary devices can be decomposed to establish a general simulation platform. Graphical representation of logic control and protection, the definition of hardware input and output can be achieved by common logic[8].

The protection logic, software attributes and hardware configuration of secondary simulation equipment can be visually configured quickly. And different algorithm files, software attribute configuration, hardware configuration can be compiled into dynamic link library (DLL) based on dynamic compiling technology, aiming to simulate different types of protection and monitoring devices [9]. To achieve the real-time simulation of secondary equipment, operating system thread is directly controlled in this program (using multi-threaded technology). So, not only multi-device emulation based on general server can be realized, but also the requirements of real-time simulation can be satisfied. Meanwhile, the simulation of multi-server communication connection of virtual secondary equipment IEC 61850 can be completed through the way that multiple IP addresses are bound to the common server NIC by secondary equipment general simulation platform. In addition, the secondary device generic simulation platform also encapsulates the actual physical device HMI, compiling it with the DLL, so that the actual secondary device panel operations and panel display can be simulated completely, and the full simulation of secondary equipment can be achieved.

\subsection{Station monitor layer use the Traffic Sniffer Technology}

To separate the secondary device pre-communication test and advanced application functions of the control layer effectively, we need to build the corresponding equivalent simulation test system. The real-time traffic sniffer of the database object by the secondary device of intelligent substation and online realtime detection can be completed by using traffic sniffer engine. The traffic sniffer engine can send the timing and data values in advance for the necessary of application function service data and can also simulate the data transmission and acquisition process. It can also realize online real-time detection for the business flow of advanced application in station monitor layer; it will automatically intercept it and complete the simulation when it finds a control command; thus it can realize the closed-loop simulation test of advanced application functions (such as reactive optimal control, onekey sequence control, intelligent operation etc.).

\subsection{The automatic test technology of secondary device}

The automatic test technology program of secondary device is shown in Fig. 3. It will generate a file when the developers compile the generated target program. The file will be imported to the intelligent substation secondary system testing platform, and the test related to all protection projects can be automatically completed, and the test report are printed, thus the mainly secondary equipment work automatic test of intelligent substation are finished. It can shorten at least 30\% and above of the test cycle of the secondary system of the intelligent substation. At the same time, the platform can be applied to the field of intelligent substation maintenance work, and it can verify the secondary device effectively, thereby reducing the workload of verification. The plug and play of secondary equipment will be realized in the future.

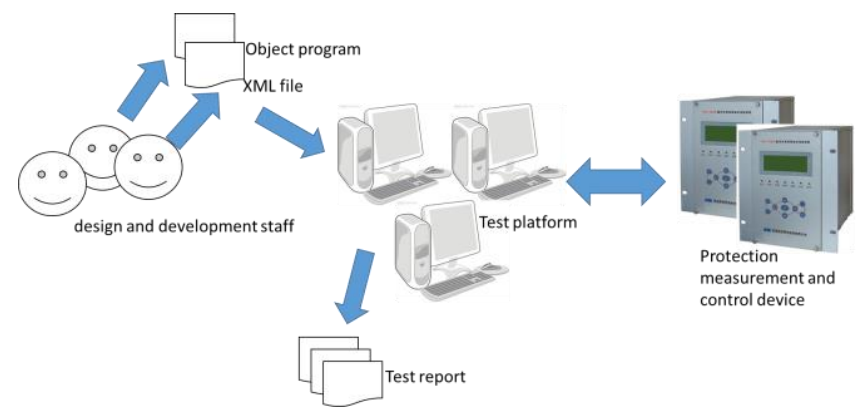

Fig. 3 The automatic test technology program of secondary device

TABLE 1 TESTING PROCESS REPORT

\begin{tabular}{|c|c|}
\hline Time(h/min/s/ms) & Test process \\
\hline 11:55:38:106 & Read data successfully \\
\hline 11:55:38:114 & Starting connecting test device \\
\hline $11: 55: 38: 114$ & Connecting test device... \\
\hline $11: 55: 42: 222$ & Complete the connection of the test device \\
\hline $11: 55: 42: 254$ & Send global configuration \\
\hline $11: 55: 42: 427$ & Send global configuration successfully \\
\hline $11: 55: 43: 227$ & Send test point data \\
\hline $11: 55: 44: 563$ & Enter normal state \\
\hline $11: 55: 59: 425$ & Protection trip \\
\hline $11: 55: 59: 441$ & Jump into state \\
\hline $11: 55: 59: 492$ & \\
\hline
\end{tabular}


TABLE2 TEST RESULT

\begin{tabular}{|c|c|c|}
\hline & test project & Test result \\
\hline \multirow{5}{*}{$\begin{array}{c}\text { II step } \\
\text { Zero sequence } \\
\text { current } \\
\text { protection }\end{array}$} & $\begin{array}{l}1.05 \text { times forward reliable } \\
\text { action }\end{array}$ & $\begin{array}{l}343.283 \mathrm{~ms} \\
\text { action }\end{array}$ \\
\hline & $\begin{array}{l}1.2 \text { times forward action time } \\
\text { check }\end{array}$ & $\begin{array}{l}343.108 \mathrm{~ms} \\
\text { action }\end{array}$ \\
\hline & $\begin{array}{l}0.95 \text { times the reverse } \\
\text { reliability does not move }\end{array}$ & $\begin{array}{l}\text { Reliable not } \\
\text { action }\end{array}$ \\
\hline & $\begin{array}{l}1.05 \text { times the reverse } \\
\text { reliability does not move }\end{array}$ & $\begin{array}{l}\text { Reliable not } \\
\text { action }\end{array}$ \\
\hline & $\begin{array}{l}0.95 \text { times forward reliable } \\
\text { action }\end{array}$ & $\begin{array}{l}\text { Reliable not } \\
\text { action }\end{array}$ \\
\hline \multirow{3}{*}{$\begin{array}{c}\text { I step } \\
\text { phase distance } \\
\text { protection }\end{array}$} & $\begin{array}{l}1.05 \text { times reliable without } \\
\text { action }\end{array}$ & $\begin{array}{l}\text { Reliable not } \\
\text { action }\end{array}$ \\
\hline & 0.95 times reliable action & $39.586 \mathrm{~ms}$ action \\
\hline & $\begin{array}{l}0.8 \text { times the action time } \\
\text { check }\end{array}$ & $39.118 \mathrm{~ms}$ action \\
\hline \multirow{3}{*}{$\begin{array}{l}\text { I step } \\
\text { grounding } \\
\text { distance } \\
\text { protection }\end{array}$} & $\begin{array}{l}1.05 \text { times reliable without } \\
\text { action }\end{array}$ & $\begin{array}{l}\text { Reliable not } \\
\text { action }\end{array}$ \\
\hline & 0.95 times reliable action & $36.835 \mathrm{~ms}$ action \\
\hline & $\begin{array}{l}0.8 \text { times the action time } \\
\text { check }\end{array}$ & $36.353 \mathrm{~ms}$ action \\
\hline
\end{tabular}

\section{Conclusions}

The test results show that this novel secondary system simulation test scheme of intelligent substation will be able to test all the items in the list, the testing scheme can fully meet the test requirements of protection device, testing process reports are shown in Table 1, part of the test results are shown in Table 2. The configuration process and configuration interface logic of the system is clear and concise, the whole simulation process is stable and reliable, the operation is simple, it can automatically set the control word, automatically read the value in the condition of no attendance, greatly improves the test efficiency.

\section{Acknowledgment}

This work was supported by the science project Fujian Electric Power Co., Ltd.( 52130414003Y).

\section{References}

[1] LIU Huan-zhi, HU Jian-feng, LI Feng, et al. Design and implementation of simulation test system for substation automation[J]. Automation of Electric Power Systems, 2012, 36(9): 109-112.

[2] LIANG Xu, ZHANG Ping, HU Ming-liang, et al. Hybrid simulating and training system of substation based on real-time simulation technology[J]. Automation of Electric Power Systems, 2005, 29(10): 79-81.

[3] Chen Hong, Huang Guofang, Chen Jinmeng, et al. Based on IEC 61850 substation secondary system engineering commissioning and quality control $[\mathrm{J}]$. electric power construction, 2012, 33 (9) : 15-19.

[4] Zhu Weijun, Tang Zhijun, Lin Ye. Research on the acceptance criteria of the two system of intelligent substation $[\mathrm{J}]$. electric power and electrical engineering, 2012, 32 (4): 16-19.

[5] Liu Haoyu, Zuo Qunye, Zhang Baoshan. Testing and analysis of the performance of the process layer network in the intelligent substation $[\mathrm{J}]$. power system protection and control, 2012, 40 (18): 112-116

[6] FAN Chen, NI Yi-min, DOU Ren-hui, et al. Interpretation of relevant specifications of integrated supervision and control systems in smart substations[J]. Automation of Electric Power Systems, 2012, 36(19): 1-5.

[7] WANG Lei, SUN Xiao-fei. Primary technology difference on the second system of smart substation with conventional substation[J]. Northeast Electric Power Technology, 2012, 33(2): 18-20.

[8] Lin Ye, Tang Zhijun, Deng Chaoping, et al. Research on the field debugging technology of intelligent substation secondary system $[\mathrm{J}]$. electric power and electrical engineering, 2012, 32 (2): 4-7.

[9] LIANG Xu, ZHANG Ping, HU Ming-liang, et al. Hybrid simulating and training system of substation based on real-time simulation technology[J]. Automation of Electric Power Systems, 2005, 29(10): 79-81.

[10] FENG Zheng-wei, BI Tian-shu, XU Gui-guang. Simulation and analysis system for substation operation[J]. Electric Power Automation Equipment, 2009 , $105-108$ 